\title{
Clinicopathological and therapeutic analysis of primary breast squamous cell carcinoma
}

\author{
Zhiying Chen, Ning An, Lei Zhang, Huanliang Cui, Yuqi Jiang, Yongchun Zhang \\ Department of Radiation Oncology, The Affiliated Hospital of Qingdao University, Qingdao, China \\ Contributions: (I) Conception and design: Z Chen; (II) Administrative support: Y Zhang; (III) Provision of study materials or patients: Y Zhang; (IV) \\ Collection and assembly of data: All authors; (V) Data analysis and interpretation: N An; (VI) Manuscript writing: All authors; (VII) Final approval of \\ manuscript: All authors. \\ Correspondence to: Yongchun Zhang. Department of Radiation Oncology, The Affiliated Hospital of Qingdao University, 16 Jiangsu Road, Shinan \\ District, Qingdao 266000, China. Email: zyc18661805058@163.com.
}

\begin{abstract}
Background Primary squamous cell carcinoma (PSCC) of the breast is a rare type of breast cancer that exhibits unique biological behavior. The pathogenesis, clinical manifestations, and effective treatment methods of this breast cancer are still unclear.
\end{abstract}

Methods: We collected all breast PSCC patients who were treated in our hospital from June 2010 to December 2018 for retrospective analysis. The clinical, pathological, treatment, and prognostic characteristics of all patients were described and compared to past breast PSCC data, to provide advice on the diagnosis and treatment for breast PSCC.

Results: We identified 35 patients with breast PSCC treated at our hospital during this period. Preoperative ultrasound showed cystic hypoechoic nodules and abundant blood flow signals in $83.33 \%$ of the cases. Postoperative pathology showed that the average diameter of the breast mass was $27.51 \mathrm{~mm}$, and $34.29 \%$ of the patients had poor differentiation. A total of 33 patients had negative expression of estrogen receptor (ER) and progesterone receptor (PR), and 32 patients had no overexpression of buman epidermal growth factor receptor 2 (HER2). The average follow-up time was 36.29 months. There were 3 cases of local recurrence, 2 cases of distant metastasis, and 1 case of natural death.

Conclusions: Breast PSCC has a special biological behavior. Surgery is the main treatment, platinumcontaining chemotherapy may be more effective for breast PSCC. Radiotherapy can reduce local recurrence, but the scope and dose of radiotherapy need to be further confirmed.

Keywords: Breast squamous cell carcinoma; pathology; treatment; prognosis

Submitted Oct 29, 2021. Accepted for publication Jan 11, 2022.

doi: $10.21037 /$ gs-21-810

View this article at: https://dx.doi.org/10.21037/gs-21-810

\section{Introduction}

Primary squamous cell carcinoma (PSCC) is a rare pathological type in breast cancer. It is an invasive type of breast cancer with unique biological behavior, and its incidence is less than $0.1 \%$ among all breast cancers (1-4). In the past, most of the studies on breast PSCC have been published in the form of a case report, and the data is currently limited. It is considered that breast PSCC is more malignant than invasive ductal carcinoma of the breast. The regional lymphatic metastasis rate is low, but it is prone to distant metastasis. The transfer rate can reach 30-33\% (5-7). At present, the definition of breast PSCC is as follows: (I) the breast tumor is not derived from the skin of the breast or the skin of the nipple, or other attachments to the skin; (II) the SCC component in the tumor tissue accounts for more than $90 \%$ after sufficient pathological examination; (III) tumors from other areas must be excluded, such as the lung, uterus, head, and neck (8-12).

Previously, it was traditionally believed that breast 
PSCC should be treated in the same way as normal breast ductal carcinoma. However, due to its special biological behavior, there is no consensus on whether breastconserving surgery, modified radical mastectomy with axillary lymph node dissection, or sentinel lymph node biopsy is more suitable for PSCC. At the same time, the choice of chemotherapeutic drugs, such as anthracyclines, cyclophosphamide, paclitaxel are effective drugs for traditional breast ductal cell carcinoma, and the effect on breast PSCC needs further statistical evidence. Tsung et al. (13) has proposed that recurrent metastatic PSCC patients are sensitive to platinum-containing chemotherapy regimens. In the molecular classification of breast, luminal A type is positive for estrogen receptor (ER) and progesterone receptor (PR), and buman epidermal growth factor receptor 2 (HER2) is negative; luminal B type means that ER, PR, and HER-2 are positive, while PSCC ER and $\mathrm{PR}$ is mostly negatively expressed, while androgen receptor (AR) is partially positively expressed, and most of HER-2 is negative, similar to triple-negative breast cancer (TNBC). Therefore, whether AR can be used as a target for endocrine therapy of breast PSCC requires further study. In recent years, a number of studies have performed biological analyses of the luminal AR subtype of TNBC, and analyzed the AR pathway, indicating that AR may be prognostic or a predictor of breast cancer. However, the current difficulty in applying an AR target to breast cancer treatment is that of how to identify patients who are most likely to benefit from AR-targeted therapy and how to select a drug combination (14-16). In the past, the scope of postoperative adjuvant radiotherapy for breast PSCC and the dose of radiotherapy were based on the development of breast ductal carcinoma (17). The efficacy of radiotherapy in the prevention of local recurrence of breast PSCC is also lacking in research. There is still controversy about the clinicopathological features and optimal treatment of the disease. Our study collected the medical history data of 35 patients with breast PSCC in our hospital, and summarized the clinicopathological characteristics, treatment and prognosis of breast PSCC. Different from previous studies, our study is not a case analysis, but a summary of dozens of patients, and comprehensively summarized experience from the clinical pathology, radiotherapy and chemotherapy and prognosis of the patients, and put forward our own ideas for the treatment of PSCC. We present the following article in accordance with the STROBE reporting checklist (available at https:// gs.amegroups.com/article/view/10.21037/gs-21-810/rc).

\section{Methods}

We collected all breast PSCC patients who were treated in our hospital from June 2010 to December 2018, and reviewed and analyzed their medical history data. The clinical, pathological, and treatment data were evaluated, and the patients were followed up to date. All procedures performed in this study involving human participants were in accordance with the Declaration of Helsinki (as revised in 2013). The study was approved by Institutional Ethics Board of The Affiliated Hospital of Qingdao University (No. QYFY WZLL 26755). Individual consent for this retrospective analysis was waived.

The diagnosis criteria were as follows: (I) postoperative pathology was fully taken, and the SCC comprised more than $90 \%$ of the mass, including spindle cell metaplasia; (II) the tumor was not derived from the breast or nipple skin; (III) the patient underwent general computed tomography (CT) examination or positron emission tomography (PET)/ CT examination before surgery, excluding tumors from the lungs, head and neck, or the cervix to metastasize to the breast. Clinical, histological, and treatment-related data were collected from medical history data and compared to data from previous breast PSCC studies. All patients underwent breast ultrasound or mammography before surgery to summarize the imaging features of the mammary gland in ultrasound or mammography. For the pathology of the breast mass, the pathology expert analyzed the slice by immunohistochemical (IHC) method to determine the ER, $\mathrm{PR}$, and AR status. The IHC staining was performed on $4 \mathrm{~mm}$ sections cut from representative paraffin blocks of breast PSCC, and the proportion of nuclear staining in tumor cells was calculated. Less than $5 \%$ was considered to be negative for ER, PR, and AR, and nuclear staining ratio was indicated in the pathology. The expression status of HER2 was calculated by counting the membrane staining ratio of tumor cells, and the immunoreactivity of HER2 was confirmed by fluorescence in situ hybridization analysis of HER2 gene copy number. The expression levels of proliferating cell nuclear protein (Ki67), epidermal growth factor receptor (EGFR), and E-cadherin were calculated by IHC.

\section{Statistical analysis}

Data were analyzed using the software SPSS22.0 (IBM Corp., Armonk, NY, USA). For numeric data, results were reported as median values \pm standard deviation (SD). The Fisher's exact and chi-square $\left(\chi^{2}\right)$ tests were used to 
Table 1 Clinical characteristics of breast PSCC patients

\begin{tabular}{lc}
\hline Clinical characteristics & Number of cases $(\mathrm{n}=35)$ \\
\hline Age (years), mean \pm SD [range] & $53.97 \pm 11.77$ [28-80] \\
Weight & 5 \\
Underweight & 21 \\
Normal weight & 9 \\
Overweight & \\
Menopausal status & 22 \\
Postmenopausal & 13 \\
Premenopausal & 0 \\
Personal history of colon cancer & 0 \\
Personal history of endometrial & \\
cancer &
\end{tabular}

PSCC, primary squamous cell carcinoma; SD, standard deviation.

compare categorical values. The $t$-test was used to compare continuous count data.

\section{Results}

\section{Clinical features}

From June 2010 to December 2018, 35 patients with breast PSCC were diagnosed in our hospital. Table 1 summarizes the clinical features of all patients. The average age was 53.97 (range, 28-80) years old.

All participants underwent breast ultrasound or mammography before surgery, and all had visible masses. Of the 35 participants, 30 underwent breast ultrasound, and $25(83.33 \%)$ had hypoechoic masses with abundant blood flow signals (Figure $1 A, 1 B$ ). Of the 35 participants, 23 underwent mammography and 15 participants showed microcalcification (Figure 1C,1D).

\section{Treatment}

All participants underwent surgery, 25 patients underwent modified radical surgery, and 10 patients underwent breast-conserving surgery. There were 4 patients who received neoadjuvant chemotherapy before surgery. The chemotherapy regimen and timing of surgery were decided by breast surgery specialists. The surgical features are summarized in Table 2.

According to the pathology of surgery, assessing the risk of recurrence and metastasis, combined with chemotherapy tolerance, 32 patients received chemotherapy, and the chemotherapy regimen was based on anthracyclines or taxanes, combined with cyclophosphamide or fluorouracil. The chemotherapy cycle was determined according to the patient's risk factors. Participants with breastconserving surgery and modified radical surgery (T3-4, $\mathrm{N}_{+}$) required postoperative adjuvant radiotherapy: 17 patients underwent adjuvant radiotherapy, 2 received conventional wedge-shaped tangential field radiotherapy, and 15 received intensity-modulated radiotherapy. The scope of radiotherapy for participants after modified radical mastectomy was the supraclavicular region and the chest wall. The range of radiotherapy target area after breastconserving surgery was determined by the number of postoperative metastatic lymph nodes and risk factors, including chest wall radiotherapy or chest wall combined with supraclavicular region. For the radiotherapy dose, the modified postoperative radiotherapy dose was as follows: planning target volume (PTV) $50 \mathrm{~Gy} / 25 \mathrm{f}$; the postoperative breast-conserving dose was the low-risk area of the whole breast, the dose given was $50 \mathrm{~Gy}$, the tumor bed area was increased by 10 Gy (continuous addition or simultaneous addition), with regular segmentation. Specific radiotherapy characteristics are shown in Table 3.

\section{Pathological features}

Table 4 summarizes the pathological features of the participants. The average diameter of tumors in all patients was $27.51 \mathrm{~mm}$ (range, 9-65 mm). The pathology of 12 participants was poorly differentiated or undifferentiated (Figure 2). The hormone receptors ER and PR were negative in 33 patients (Figure $3 A, 3 B$ ), and $\mathrm{AR}$ was positive in 6 patients. The HER2 expression was negative in 33 patients (Figure 3C). The average expression level of Ki67 in tumor tissues was $49.37 \%$. A total of 13 participants had high expression of EGFR (Figure 3D), and 19 participants had positive expression of E-cadherin. There were 9 participants with axillary lymph node metastasis. We found that postoperative pathological lymph node metastasis had no significant effect on whether patients had recurrence or metastasis $(\mathrm{P}=0.604)$, but Ki67 value was significant for patients with recurrence and metastasis $(\mathrm{P}<0.05)$. 

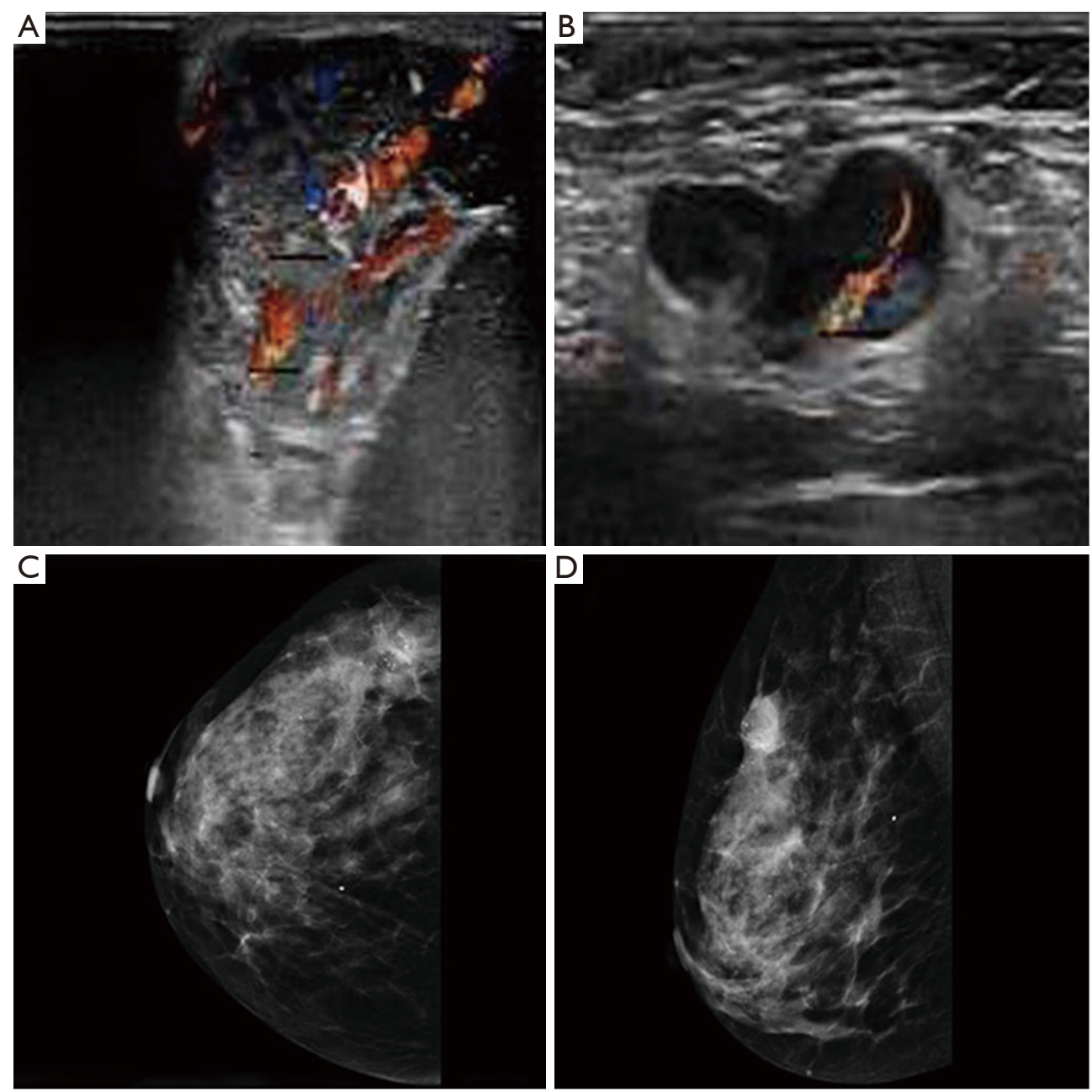

Figure 1 Imaging findings of the primary tumor. (A,B) Ultrasound showed a $8.4 \mathrm{~cm} \times 5.6 \mathrm{~cm} \times 4$ cm hypoechoic solid cystic mass in the upper outer quadrant of the left breast. Different colors represent abundant blood flow signals. (C,D) Mammogram shows an irregular density shadow in the outer breast quadrant, the edges are unclear, and there are burrs around it. Short rods and blurred calcified shadows are visible in the mass, and the size is about $22 \mathrm{~mm} \times 19 \mathrm{~mm}$.

Table 2 Surgical data of breast PSCC patients

\begin{tabular}{lc}
\hline Surgical approach & Number of cases $(n)$ \\
\hline Modified radical surgery & 25 \\
Breast-conserving surgery & 10 \\
Sentinel lymph node biopsy & 10 \\
Axillary lymph node dissection & 25 \\
\hline
\end{tabular}

PSCC, primary squamous cell carcinoma.

\section{Prognosis}

At the time of follow-up, 26 participants had no recurrence and metastasis, 3 had local recurrence, 2 had distant metastases, and 1 had died of natural age. All participants were followed up. The mean follow-up time was 36.29 months (range, 9-103 months) for all participants and the median progression-free survival (PFS) time was 35.68 months (range, 1-103 months). 
Table 3 Radiotherapy characteristics of breast PSCC patients

\begin{tabular}{lcc}
\hline Radiotherapy & Number of cases $(\mathrm{n})$ & Percentage $(\%)$ \\
\hline No radiotherapy & 18 & 51.42 \\
Conventional wedge-shaped tangential field radiotherapy & 2 & 5.71 \\
Intensity-modulated radiotherapy & 15 & 42.86 \\
Including the supraclavicular region & 13 & 37.14 \\
Does not include the supraclavicular area & 4 & 11.43 \\
\hline
\end{tabular}

PSCC, primary squamous cell carcinoma.

Table 4 Pathological features of patients with breast PSCC

\begin{tabular}{lc}
\hline Pathological features & Number of cases (n) \\
\hline Invasive component & \\
Size (mm), mean \pm SD [range] & $27.51 \pm 14.81$ [9-65] \\
Grade & 3 \\
G1 & 11 \\
G2 & 12 \\
G3 & 4 \\
Lymphatic vessel invasion & $13.97 \pm 10.06$ \\
Average number of lymph nodes obtained \\
after surgery, mean \pm SD
\end{tabular}

PSCC, primary squamous cell carcinoma; SD, standard deviation; EGFR, epidermal growth factor receptor.

\section{Discussion}

As a rare pathological type of breast malignant tumor, breast PSCC has not been studied for its biological behavior. There are two main theories about the origin of tumors in breast PSCC: (I) breast PSCC may be derived from chronic inflammation of the breast, breast abscess, or complex abscess of the breast; (II) another study found that most of the breast PSCC coexist with other breast pathological types, perhaps originating from the normal breast tissue through metaplasia. Gupta et al. (4) reported that for a patient who was initially diagnosed with a breast abscess, abscess drainage therapy was invalid, and they were finally diagnosed as breast PSCC by surgery. In our study, we found that most patients with breast PSCC showed hypoechoic cystic mass upon ultrasound and the wall thickness was different. Many studies in the past have pointed out that the majority of breast PSCC lacks the detection of bone needle or microcalcification in mammography $(18,19)$; however, our study found that many breast PSCC patients had calcification characteristics which is common in ductal carcinoma. As mammography is not specific for breast PSCC imaging, it has no advantage in the diagnosis of breast PSCC.

Previously, research on breast PSCC has mostly been reported in a case-by-case manner, and the pathology has been mixed with other pathological types of breast cancer. The research was not purely focused on breast PSCC, so the description of the disease was not accurate enough. In this study, according to the definition of breast PSCC, patients were strictly selected, and those not only with mixed cancer and the tumor origin of breast skin or nipple but also primary tumors in other areas were excluded.

Most breast PSCCs are found in postmenopausal women, and breast PSCC patients have previously been reported as aged 29-90 years (20) with an average age of onset of 50.5 years (21). The onset of breast PSCC is later than that of invasive ductal carcinoma. The mean age of the patients in this study was 53.97 years, and 22 cases were postmenopausal. In postmenopausal patients, hormone levels are decreased, and tumor tissues are negative in hormone receptor expression, so they are consistent.

Compared with invasive ductal carcinoma, breast PSCC masses tend to be larger and grow rapidly, $20-30 \%$ are larger than $5 \mathrm{~cm}$ in diameter, and often accompanied by necrosis $(22,23)$. Our study found that the rate of breast PSCC macroscopically showing an inflammatory cyst or abscess was up to $50 \%(24,25)$. Therefore, for these 

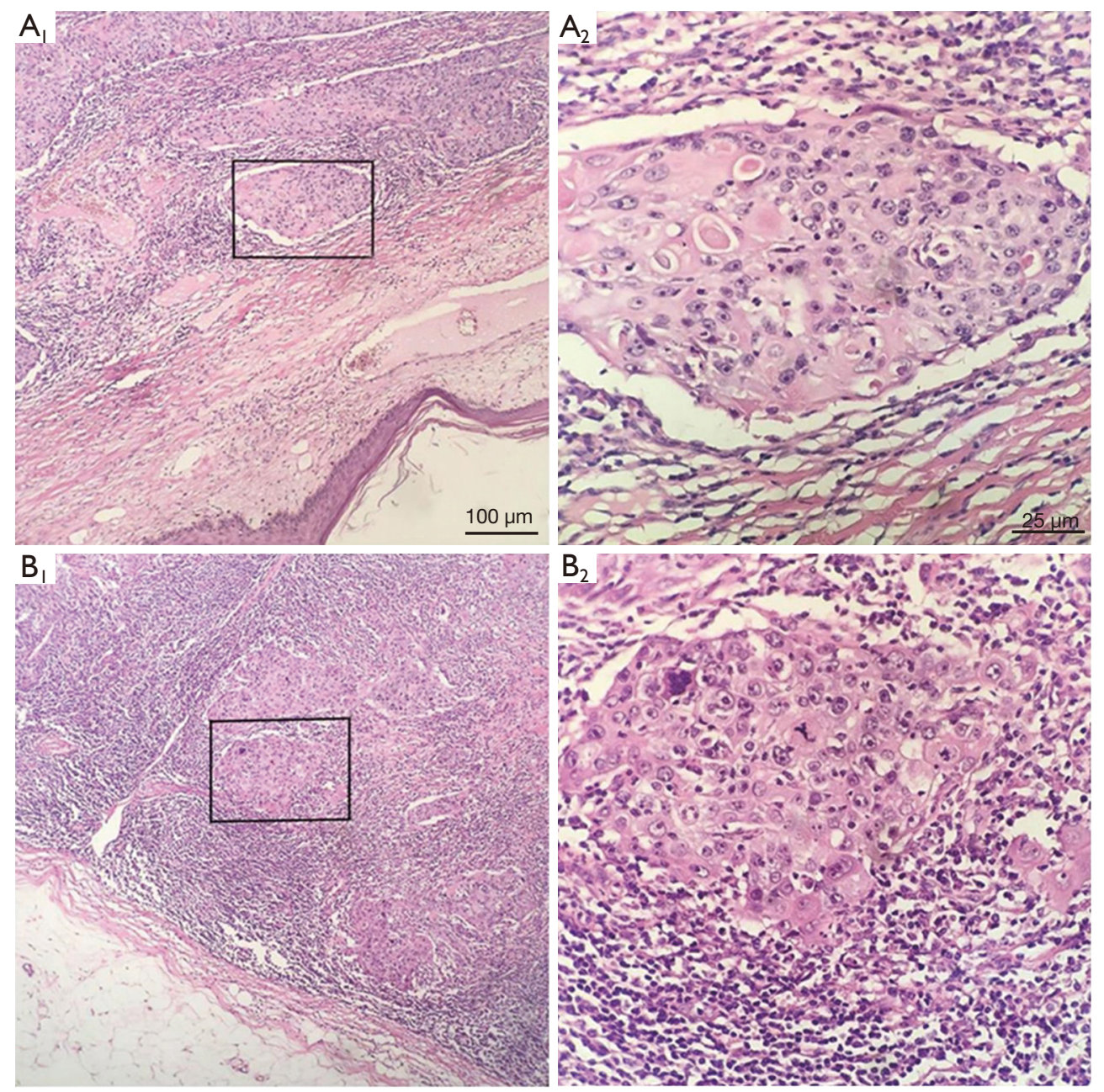

Figure 2 Histological findings with hematoxylin and eosin. (A) Microscopically, the ductal cells in the mammary tumor area show squamous degeneration, contain necrotic substances, inflammatory cells, giant cells, and malignant squamous cells arranged, showing extracellular keratinized beads. (B) Metastatic tumor in the lymph node. Magnification: $\left(A_{1}, B_{1}\right) 100 \times$ and $\left(A_{2}, B_{2}\right) 400 \times$.

patients, anti-infective treatment or abscess drainage are often not effective. At this time, the clinician is reminded of the possibility of breast PSCC, and cytological biopsy is used to determine the nature of the lesion. Biopsy study in well-differentiated breast PSCC found that flow pattern, enlarged nucleoli, dense nucleus, atypical keratinocytes, and necrotic background, which is consistent with related studies (26,27). Moreover, we found that the pathological morphology of breast PSCC is very similar to that of skin PSCC, but the growth rate of breast PSCC is faster, and its progression may be only a few months $(28,29)$. The prognosis of breast cancer of different pathological types is very different. As many breast PSCCs are poorly differentiated and difficult to distinguish from invasive ductal carcinoma or apocrine adenocarcinoma, its pathological diagnosis presents a new challenge. Kinoshita et al. (30) conducted a related study and pointed out how to distinguish between breast PSCC and ductal carcinoma or apocrine adenocarcinoma. At the same time, we found that patients with breast PSCC are often more prone to recurrence and migration. If the pathological differentiation is low, a poor prognosis is indicated. The Ki67 marker is associated with tumor proliferation and is expressed in dividing cells, and high levels of expression predict strong tumor invasiveness and poor prognosis $(31,32)$. Studies have shown that Ki67 expression levels are often associated with tumor pathological grade, lymph node metastasis, and staging, and there is an inverse relationship between 

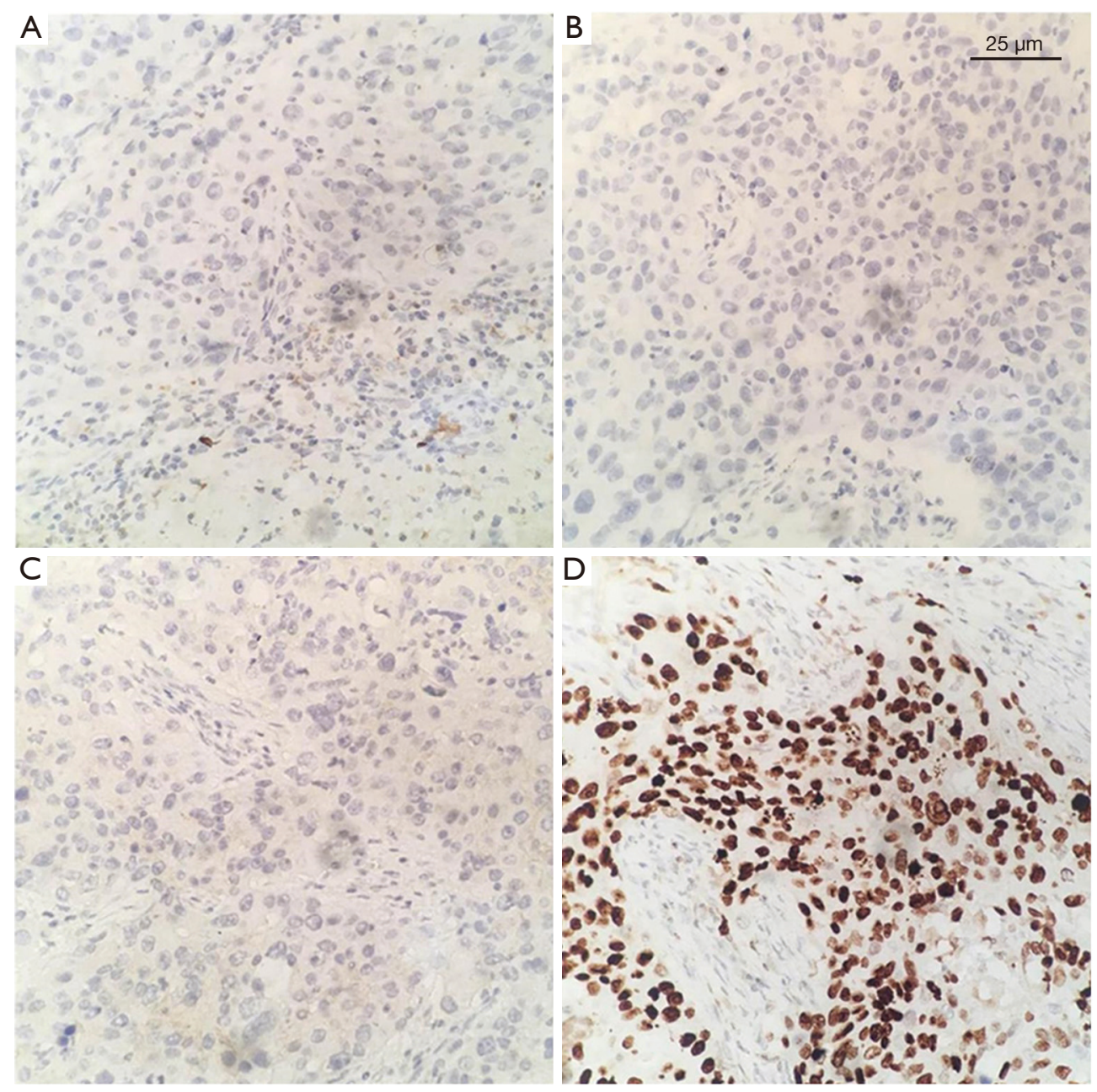

Figure 3 Photomicrograph showing tumoral area with ER and PR negativity (A,B: 400x) with HER2 receptor negativity (C: 400x), with Ki67 positive expression, the positive rate reached 97\% (D: 400x). ER, estrogen receptor; PR, progesterone receptor; HER2, human epidermal growth factor receptor 2 .

hormone receptor ER status and Ki67 expression in breast cancer (32). In this study, 34 participants were ER negative, and the average Ki67 level was as high as $49.37 \%$, which it is meaningful for recurrence and metastasis of breast cancer patients. Goldhirsch pointed out that when hormone receptors are evaluated together with HER2, Ki67 helps to classify breast cancer into different subtypes and serves as a dynamic biomarker for the selection of systemic therapy for early breast cancer (33). However, due to the lack of standard assays for Ki67 and the lack of a defined reference range for its expression level, there is disparity in its assessment of tumor prognosis (34).

Past studies have found that more than $90 \%$ of breast PSCC cases are TNBC (ER, PR, and HER2 are negative),
PFS is $2-36$ months $(5,35)$, cumulative 5 -year survival rate is $51 \%$ to $68.1 \%$, and 10 -year survival rate is $60-60.2 \%$ $(19,36,37)$. As member of the HER family, EGFR is associated with poor tumor prognosis and EGFR expression is detected in approximately $40 \%$ of breast cancers (38). Overexpression can predict breast cancer patients' poor response to endocrine therapy (39). Our IHC studies found that 14 participants were EGFR-positive, all participants were ER and PR-negative, and had poor response to hormone therapy.

Compared with breast invasive ductal carcinoma, patients with breast PSCC have a lower axillary lymph node metastasis rate $(6,7)$. Past studies have found that axillary lymph node metastasis can be seen in $10-30 \%$ of breast 
PSCC cases, but it is prone to blood diffusion and distant metastasis $(5,6,40)$. In the present study, $9(16.77 \%)$ of 35 participants had axillary lymph node metastasis, and lymph node metastasis had no significant effect on whether there is recurrence or metastasis in breast PSCC patients. As most of the patients with multiple metastases in the postoperative lymph nodes were diagnosed in 2018 and the follow-up cycle time was too short, a longer period of following up is needed. The rate of lymph node metastasis of breast ductal carcinoma is $40-60 \%$, and the incidence of PSCC in the breast is low. Therefore, we may consider that it is more appropriate to recommend sentinel lymph node biopsy. At the same time, this study found that breast masses are often larger in the diagnosis of breast PSCC, so modified radical surgery may be more suitable for breast cancer patients than breast-conserving surgery.

Breast-conserving surgery, modified radical surgery, and local radiotherapy can effectively reduce the local recurrence rate and improve the survival rate of breast cancer. Related studies have pointed out that especially after breast-conserving breast cancer, radiotherapy will reduce the recurrence rate of breast cancer by half and the mortality rate by about one-sixth $(41,42)$. Radiotherapy combined with the breast-conserving surgery can achieve cosmetic results while achieving the effect of mastectomy. In this study, according to the risk assessment of postoperative recurrence, combined with the patient's physical condition and willingness, 17 participants underwent postoperative adjuvant radiotherapy, 1 patient with recurrence of chest wall with radiotherapy, and 2 patients with recurrence of chest wall without radiotherapy. There was 1 patient with ductal carcinoma after breast cancer surgery, local recurrence after 2 years, and contralateral axillary lymph node metastasis. The pathology after recurrence was SCC. Therefore, the radiation history proposed in other studies such as that by Singh et al. (43) may reveal breast PSCC. Past research indicates that breast PSCC (44-46) has appeared in other cases of silicone breast augmentation. This may indicate that patients with previous special medical history are at a higher risk of developing breast PSCC. In this study, patients with breast PSCC were treated with postoperative adjuvant radiotherapy according to the postoperative pathological results and the patient's tolerance. Radiotherapy was found to be important for reducing the risk of local recurrence. However, due to the limited number of patients, large-scale data is needed to confirm the significance of this conclusion and the appropriate radiotherapy protocol for breast PSCC.
The prognosis of breast PSCC is currently very limited, and most reports indicate that breast PSCC is an invasive tumor. The standard treatment regimen is currently not uniform in comparison with ductal carcinoma $(47,48)$. Surgery is an important treatment for breast PSCC and is the first choice for early breast cancer. Similar to TNBC, the majority of breast PSCC hormone receptors ER and $\mathrm{PR}$ are negative, and conventional hormone therapy is ineffective, but AR is partially positive in this type of tumor, so the efficacy of AR blocker remains to be further studied. The expression of HER2 is negative in such patients, so the targeted therapy, such as trastuzumab, is ineffective. Chemotherapeutic drugs that are usually effective for ductal carcinoma are not effective in breast PSCC $(5,40)$. Previously, many studies have recommend that breast PSCC can be treated with 5-fluorouracil and cisplatin with or without anthracycline $(6,49)$, but studies have also shown that breast PSCC is naturally resistant to fluorouracil, cyclophosphamide, and anthracyclines, and may be sensitive to platinum-based chemotherapy (50). In this study, the patient's chemotherapy regimen was based on anthracycline or paclitaxel, combined with cyclophosphamide or fluorouracil, and 2 patients had local recurrence or distant metastasis during their chemotherapy cycle. Therefore, anthracycline-based or paclitaxel-based chemotherapy is considered to be effective in reducing recurrence and metastasis of breast PSCC. Due to limited data, the choice of chemotherapy regimen for breast PSCC remains to be further clinically studied. In this study, we found that there was a high expression of EGFR in breast PSCC tissues, so whether the application of EGRF monoclonal antibody combined with chemotherapy in breast PSCC can improve the efficacy remains to be confirmed.

Combined with the clinicopathological characteristics of breast PSCC, in the diagnosis, the mass of breast PSCC tends to appear as a large cystic solid mass, similar to an early breast abscess. Ultrasound imaging of the breast has advantages over mammography. If necessary, a biopsy should be performed to confirm the nature of the lesion. To summarize the treatment and prognosis of 35 patients with breast PSCC, we consider that because of the large local masses in breast PSCC patients and the low postoperative axillary lymph node metastasis rate, we can recommend modified radical surgery combined with sentinel lymph node biopsy. Most breast PSCC hormone receptors are negative for ER and PR and are not sensitive to endocrine therapy. Therefore, the significance of chemotherapy for breast PSCC may be more important, but the choice of 
chemotherapy regimens may require more clinical data. Many of our patients have a disease-free survival period of more than 5 years after postoperative radiotherapy, suggesting that radiotherapy can help reduce the local recurrence of breast PSCC, but the scope and dose of radiotherapy need to be further confirmed.

\section{Conclusions}

Breast PSCC has a special biological behavior, which is more aggressive than traditional breast cancer and has a worse prognosis. Surgery is the main treatment method, and platinum-containing chemotherapy may be more effective for breast PSCC. Radiotherapy can reduce local recurrence, but the scope and dose of radiotherapy need to be further confirmed. For breast PSCC, further prospective clinical studies are needed to provide new methods for its treatment.

\section{Acknowledgments}

Funding: None.

\section{Footnote}

Reporting Checklist: The authors have completed the STROBE reporting checklist. Available at https:// gs.amegroups.com/article/view/10.21037/gs-21-810/rc

Data Sharing Statement: Available at https://gs.amegroups. com/article/view/10.21037/gs-21-810/dss

Conflicts of Interest: All authors have completed the ICMJE uniform disclosure form (available at https://gs.amegroups. com/article/view/10.21037/gs-21-810/coif). The authors have no conflicts of interest to declare.

Ethical Statement: The authors are accountable for all aspects of the work in ensuring that questions related to the accuracy or integrity of any part of the work are appropriately investigated and resolved. All procedures performed in this study involving human participants were in accordance with the Declaration of Helsinki (as revised in 2013). The study was approved by Institutional Ethics Board of The Affiliated Hospital of Qingdao University (No. QYFY WZLL 26755). Individual consent for this retrospective analysis was waived.

Open Access Statement: This is an Open Access article distributed in accordance with the Creative Commons Attribution-NonCommercial-NoDerivs 4.0 International License (CC BY-NC-ND 4.0), which permits the noncommercial replication and distribution of the article with the strict proviso that no changes or edits are made and the original work is properly cited (including links to both the formal publication through the relevant DOI and the license). See: https://creativecommons.org/licenses/by-nc-nd/4.0/.

\section{References}

1. Weigel RJ, Ikeda DM, Nowels KW. Primary squamous cell carcinoma of the breast. South Med J 1996;89:511-5.

2. Arffmann E, Hojgaard K. Squamous carcinoma of the breast: report of a case. J Pathol Bacteriol 1965;90:319-20.

3. Brack K, Ramaekers PC, Tjalma WA. Primary squamous cell carcinoma of the breast. Eur J Gynaecol Oncol 2003;24:384-6.

4. Gupta C, Malani AK, Weigand RT, et al. Pure primary squamous cell carcinoma of the breast: a rare presentation and clinicopathologic comparison with usual ductal carcinoma of the breast. Pathol Res Pract 2006;202:465-9.

5. Behranwala KA, Nasiri N, Abdullah N, et al. Squamous cell carcinoma of the breast: clinicopathologic implications and outcome. Eur J Surg Oncol 2003;29:386-9.

6. Menes T, Schachter J, Morgenstern S, et al. Primary squamous cell carcinoma (SqCC) of the breast. Am J Clin Oncol 2003;26:571-3.

7. Zanconati F, Zanella M, Falconieri G, et al. Gestational squamous cell carcinoma of the breast: an unusual mammary tumor associated with aggressive clinical course. Pathol Res Pract 1997;193:783-7; discussion 789-90.

8. Dejager D, Redlich PN, Dayer AM, et al. Primary squamous cell carcinoma of the breast: sensitivity to cisplatinum-based chemotherapy. J Surg Oncol 1995;59:199-203.

9. Cappellani A, Di Vita M, Zanghì A, et al. A pure primary squamous cell breast carcinoma presenting as a breast abscess: case report and review of literature. Ann Ital Chir 2004;75:259-62; discussion 262-3.

10. Gupta S, Usha. Primary squamous cell carcinoma of the breast arising within an abscess. J Indian Med Assoc 1982;79:12-3.

11. Ribeiro-Silva A, Luzzatto F, Chang D, et al. Limitations of fine-needle aspiration cytology to diagnose metaplastic carcinoma of the breast. Pathol Oncol Res 2001;7:298-300.

12. Prasad N, Prasad P. A case of pure primary squamous cell 
carcinoma of the breast diagnosed by fine needle aspiration biopsy. Indian J Pathol Microbiol 1988;31:71-2.

13. Tsung SH. Primary pure squamous cell carcinoma of the breast might be sensitive to Cisplatin-based chemotherapy. Case Rep Oncol 2012;5:561-5.

14. Kono M, Fujii T, Lim B, et al. Androgen Receptor Function and Androgen Receptor-Targeted Therapies in Breast Cancer: A Review. JAMA Oncol 2017;3:1266-73.

15. Gucalp A, Tolaney S, Isakoff SJ, et al. Phase II trial of bicalutamide in patients with androgen receptor-positive, estrogen receptor-negative metastatic Breast Cancer. Clin Cancer Res 2013;19:5505-12.

16. Traina TA, Miller K, Yardley DA, et al. Enzalutamide for the Treatment of Androgen Receptor-Expressing TripleNegative Breast Cancer. J Clin Oncol 2018;36:884-90.

17. Boyages J. Radiation therapy and early breast cancer: current controversies. Med J Aust 2017;207:216-22.

18. Wargotz ES, Norris HJ. Metaplastic carcinomas of the breast: V. Metaplastic carcinoma with osteoclastic giant cells. Hum Pathol 1990;21:1142-50.

19. Grabowski J, Saltzstein SL, Sadler G, et al. Squamous cell carcinoma of the breast: a review of 177 cases. Am Surg 2009;75:914-7.

20. Chatha SS, Bano R, Farooq M, et al. Squamous Cell Carcinoma of the Breast. J Coll Physicians Surg Pak 2018;28:776-8.

21. Siegelmann-Danieli N, Murphy TJ, Meschter SC, et al. Primary pure squamous cell carcinoma of the breast. Clin Breast Cancer 2005;6:270-2.

22. Hennessy BT, Krishnamurthy S, Giordano S, et al. Squamous cell carcinoma of the breast. J Clin Oncol 2005;23:7827-35.

23. Liu J, Yu Y, Sun JY, et al. Clinicopathologic characteristics and prognosis of primary squamous cell carcinoma of the breast. Breast Cancer Res Treat 2015;149:133-40.

24. Salemis NS. Breast abscess as the initial manifestation of primary pure squamous cell carcinoma: a rare presentation and literature review. Breast Dis 2011;33:125-31.

25. Nair VJ, Kaushal V, Atri R. Pure squamous cell carcinoma of the breast presenting as a pyogenic abscess: a case report. Clin Breast Cancer 2007;7:713-5.

26. $\mathrm{Ng} \mathrm{WK}$, Kong JH. Significance of squamous cells in fine needle aspiration cytology of the breast. A review of cases in a seven-year period. Acta Cytol 2003;47:27-35.

27. Jain M. An overview on "cellular cannibalism" with special reference to oral squamous cell carcinoma. Exp Oncol 2015;37:242-5.

28. Sharma R, Usmani S, Siegel R. Primary squamous cell carcinoma of breast in background of phyllodes tumor--a case report. Conn Med 2009;73:341-3.

29. Cichon P, Drucis K, Piotrkowski J. Primary squamous cell carcinoma of the breast - a case report. Pol Merkur Lekarski 2015;38:140-3.

30. Kinoshita M, Matsuda Y, Arai T, et al. Cytological diagnostic clues in poorly differentiated squamous cell carcinomas of the breast: Streaming arrangement, necrotic background, nucleolar enlargement and cannibalism of cancer cells. Cytopathology 2018;29:22-7.

31. de Azambuja E, Cardoso F, de Castro G Jr, et al. Ki-67 as prognostic marker in early breast cancer: a meta-analysis of published studies involving 12,155 patients. Br J Cancer 2007;96:1504-13.

32. Inwald EC, Klinkhammer-Schalke M, Hofstädter F, et al. $\mathrm{Ki}-67$ is a prognostic parameter in breast cancer patients: results of a large population-based cohort of a cancer registry. Breast Cancer Res Treat 2013;139:539-52.

33. Goldhirsch A, Wood WC, Coates AS, et al. Strategies for subtypes--dealing with the diversity of breast cancer: highlights of the St. Gallen International Expert Consensus on the Primary Therapy of Early Breast Cancer 2011. Ann Oncol 2011;22:1736-47.

34. American Society of Clinical Oncology 2007 Update of Recommendations for the Use of Tumor Markers in Breast Cancer. J Oncol Pract 2007;3:336-9.

35. Bouchalova K, Cizkova M, Cwiertka K, et al. Triple negative breast cancer--current status and prospective targeted treatment based on HER1 (EGFR), TOP2A and C-MYC gene assessment. Biomed Pap Med Fac Univ Palacky Olomouc Czech Repub 2009;153:13-7.

36. Valdehita A, Carmena MJ, Bajo AM, et al. RNA interference-directed silencing of VPAC1 receptor inhibits VIP effects on both EGFR and HER2 transactivation and VEGF secretion in human breast cancer cells. Mol Cell Endocrinol 2012;348:241-6.

37. Murialdo R, Boy D, Musizzano Y, et al. Squamous cell carcinoma of the breast: a case report. Cases J 2009;2:7336.

38. Grenier J, Soria JC, Mathieu MC, et al. Differential immunohistochemical and biological profile of squamous cell carcinoma of the breast. Anticancer Res 2007;27:547-55.

39. Nayak A, Wu Y, Gilcrease MZ. Primary squamous cell carcinoma of the breast: predictors of locoregional recurrence and overall survival. Am J Surg Pathol 2013;37:867-73.

40. Aparicio I, Martínez A, Hernández G, et al. Squamous cell carcinoma of the breast. Eur J Obstet Gynecol Reprod Biol 2008;137:222-6. 
41. Early Breast Cancer Trialists' Collaborative Group (EBCTCG); Darby S, McGale P, et al. Effect of radiotherapy after breast-conserving surgery on 10year recurrence and 15-year breast cancer death: metaanalysis of individual patient data for 10,801 women in 17 randomised trials. Lancet 2011;378:1707-16.

42. EBCTCG (Early Breast Cancer Trialists' Collaborative Group); McGale P, Taylor C, et al. Effect of radiotherapy after mastectomy and axillary surgery on 10-year recurrence and 20-year breast cancer mortality: metaanalysis of individual patient data for 8135 women in 22 randomised trials. Lancet 2014;383:2127-35.

43. Singh H, Williams SP, Kinsella V, et al. Postradiation squamous cell cancer of the breast. Cancer Invest 2000;18:343-6.

44. Talmor M, Rothaus KO, Shannahan E, et al. Squamous cell carcinoma of the breast after augmentation with liquid silicone injection. Ann Plast Surg 1995;34:619-23.

45. Smith LF, Smith TT, Yeary E, et al. Squamous cell

Cite this article as: Chen Z, An N, Zhang L, Cui H, Jiang Y, Zhang Y. Clinicopathological and therapeutic analysis of primary breast squamous cell carcinoma. Gland Surg 2022;11(1):125-135. doi: 10.21037/gs-21-810 carcinoma of the breast following silicone injection of the breasts. J Okla State Med Assoc 1999;92:126-30.

46. Paletta C, Paletta FX Jr, Paletta FX Sr. Squamous cell carcinoma following breast augmentation. Ann Plast Surg 1992;29:425-9; discussion 429-32.

47. Tayeb K, Saâdi I, Kharmash M, et al. Primary squamous cell carcinoma of the breast. Report of three cases. Cancer Radiother 2002;6:366-8.

48. Moisidis E, Ahmed S, Carmalt H, et al. Primary squamous cell carcinoma of the breast. ANZ J Surg 2002;72:65-7.

49. Wrightson WR, Edwards MJ, McMasters KM. Primary squamous cell carcinoma of the breast presenting as a breast abscess. Am Surg 1999;65:1153-5.

50. Cilekar M, Erkasap S, Oner U, et al. An atypical cause of rapidly progressing breast lump with abscess formation: Pure squamous cell carcinoma of the breast. J Cancer Res Ther 2015;11:1023.

(English Language Editor: J. Jones) 